\title{
Sociodemographic factors, health seeking behaviors, reproductive history, and knowledge of cervical screening among women in Swaziland
}

Ibironke O. Aina' ${ }^{1}$, Smruti M. Raul', Luz A. Padilla', Simangele Mthethwa-Hleta², Peter O. Preko ${ }^{3}$ and Pauline E. Jolly ${ }^{1 *}$ (D)

\begin{abstract}
Background: Cervical cancer is the leading cause of cancer among women in Swaziland; however, a low rate of cervical screening in this population has led to high rates of morbidity and mortality from cervical cancer.

Objective: To identify factors associated with lack of cervical screening among women in Swaziland.

Methods: A cross-sectional study was conducted among 300 women aged 18-69 years attending clinics in three regions of Swaziland from May to August of 2014. An investigator-administered questionnaire was used to collect data on socioeconomic factors, health-seeking behaviors, reproductive history, and cervical screening history and knowledge from the women.

Results: Adjusted multivariable logistic regression analysis revealed that women $<30$ years of age were less likely to receive a cervical exam compared to women $\geq 30$ years of age (Odds Ratio $0.06,95 \%$ Confidence Interval 0.01-0.67). Women who had a tertiary education were almost 6 times more likely to receive a cervical screening (OR 5.83, 95\% $\mathrm{Cl} 1.11-30.50$ ). Women who said that they did not know when to receive cervical screening were $73 \%$ less likely to have a cervical exam (OR 0.27, 95\% Cl 0.01-0.74).

Conclusions: Younger age, lower educational level, and lack of knowledge about when to receive a cervical screening affected whether women obtained a cervical screening. This indicates the need for educating women, particularly younger women, about the importance of cervical examinations. Addressing these barriers to screening should lead to a decrease in cervical lesions and cancer, especially in this high HIV-positive population.
\end{abstract}

Keywords: Swaziland, Cervical screening, Sociodemographic factors, Health-seeking behaviors, Reproductive history, Knowledge of cervical cancer, Visual inspection with acetic acid

\footnotetext{
*Correspondence: jollyp@uab.edu

'Department of Epidemiology, School of Public Health, University of

Alabama at Birmingham, 1655 University Boulevard, Birmingham, AL 35294-0022, USA

Full list of author information is available at the end of the article
}

(C) The Author(s). 2020 Open Access This article is licensed under a Creative Commons Attribution 4.0 International License, which permits use, sharing, adaptation, distribution and reproduction in any medium or format, as long as you give appropriate credit to the original author(s) and the source, provide a link to the Creative Commons licence, and indicate if changes were made. The images or other third party material in this article are included in the article's Creative Commons licence, unless indicated otherwise in a credit line to the material. If material is not included in the article's Creative Commons licence and your intended use is not permitted by statutory regulation or exceeds the permitted use, you will need to obtain permission directly from the copyright holder. To view a copy of this licence, visit http://creativecommons.org/licenses/by/4.0/ The Creative Commons Public Domain Dedication waiver (http://creativecommons.org/publicdomain/zero/1.0/) applies to the data made available in this article, unless otherwise stated in a credit line to the data. 


\section{Background}

Cervical cancer (CC) is the fourth most common cancer among women worldwide and the number one cancer among women in sub-Saharan Africa [1]. Over 85\% of the global burden of $\mathrm{CC}$ occurs in resource-limited countries [1]. There are 530,000 new CC cases and 275,000 deaths related to $\mathrm{CC}$ annually. Most of the morbidity and mortality from $\mathrm{CC}$ occurs because of low cervical screening rates (19\% on average) among women in developing countries [2]. Many women do not visit health care facilities until they are in the advanced stages of $\mathrm{CC}$.

Almost all cases of CC are caused by oncogenic strains of the Human Papillomavirus (HPV) [3-6]. In women with healthy immune systems, most HPV infections are transient and are eventually cleared from the body. There are an estimated 380 new cases of CC annually in Swaziland [7]. A recent study from Swaziland showed that the prevalence of high-risk-HPV (hr-HPV) infection was high and significantly associated with HIV among sexually active women [8]. The estimated overall prevalence of hr-HPV was $46.2 \%$ and decreased with increasing age. The overall HIV prevalence among the women was $42.7 \%$ and HIV-positive women were 5 times more likely to be infected with hr-HPV and to have multiple group hr-HPV infections [8]. The overall hr-HPV/HIV co-infection was $24.4 \%$ and was significantly higher among younger women [8]. Thus, the risk of cervical lesions among HIV-positive women in Swaziland is 4 to 5 times higher than among HIV-negative women [9]. Swaziland has the highest HIV prevalence rate (27.4\%) in the world, with women of reproductive age (15-49 years) making up more than half of all HIV infections in the country [10]. The HIV prevalence among pregnant women in Swaziland is estimated at 39.2\% [11]. With regard to factors associated with cervical lesions, we found that women who had $\geq 2$ lifetime sexual partners and women with a history of sexually transmitted infections (STIs) were three and two times more likely, respectively, to have cervical lesions compared to women with one lifetime partner and no previous STIs [9].

Other studies have identified factors such as smoking, sexual debut before age 16 , age $<40$ years, CD4 count $<$ 650 cells, $\geq 5$ abortions, and other vaginal wall abnormalities to be associated with cervical lesions or invasive CC [12-14]. Furthermore, factors such as knowledge and attitudes towards cervical screening, as well as availability and accessibility of services, will determine the extent to which women will participate in screening and other health services [15].

Due to the lack of technical, infrastructural, financial, and human resources needed for cytology-based screening in many developing countries, visual inspection with acetic acid (VIA) is the cervical screening method most commonly used in low-income countries, including
Swaziland [16]. During cervical screening, physicians apply acetic acid to the cervix to determine if there are any lesions. VIA is considered a more efficient option due to rapid exam results that allows for immediate treatment when necessary $[16,17]$.

In this study, we investigated sociodemographic factors, health-seeking behaviors, knowledge of CC screening and accessibility in relation to cervical screening history among a sample of women, including HIVpositive women, attending health clinics in Swaziland. It is essential to understand women's health-seeking behaviors and knowledge of cervical screening so that appropriate interventions can be implemented to increase screening uptake, which could lead to a decrease in CC cases.

\section{Methods}

A cross-sectional study was conducted among 300 women (150 HIV-positive and 150 HIV-negative) 18-69 years of age. The women were recruited from three hospitals in Swaziland that were able to perform cryotherapy and VIA, namely Mbabane Hospital in the Hhohho Region, the Raleigh Fitkin Memorial (RFM) Hospital in the Manzini Region, and the Hlatikulu Hospital in the Shiselweni Region. HIV-positive women were recruited from antiretroviral therapy (ART) clinics and HIV treatment and care (HTC) sites at outpatient departments (OPDs) of the hospitals. The comparison group was women who tested HIV-negative at the OPDs.

Clinic staff informed the women of the study and asked if they would be willing to participate. Women who expressed interest in participating were introduced to the study staff who told them about the purpose and procedures of the study. Participants were guaranteed full confidentiality and participation was voluntary. The women were told that they could refuse participation and withdraw from the study at any time. The women read the informed consent form and were encouraged to ask questions prior to signing the form. After participants provided signed consent, an interviewer-administered questionnaire was used to collect information on: 1) Sociodemographic factors, HIV status, and cervical screening (age, marital status, income, education, employment status, occupation); 2) CC knowledge and use of health care services (family history of CC, frequency of use of health care facilities); 3) Knowledge and perceptions regarding cervical screening (knowing which test to have, knowing when to be screened, worry about screening results, cost of screening, screening test is painful, embarrassing and/or uncomfortable); and 4) Reproductive history and sexual practices (parity, breastfeeding, contraception use, sexual partners, condom use, history of STIs). Each participant was assigned a unique identification (ID) number that was placed on their questionnaire; no personal identifying information was written 
on the questionnaire. To help ensure confidentiality, the interviews were conducted in private hospital rooms. Once the interview was complete, clinic staff used VIA to screen the participants for cervical lesions.

\section{Data analysis}

Data were analyzed for 297 women, three of the women were excluded from the analysis due to unknown HIV status; 87 of the 297 women (29.3\%) previously received a cervical exam and 210 had not. Sociodemographic, sexual, and reproductive history variables were stratified according to whether the women reported that they had a previous cervical exam. Descriptive statistics (frequencies, percentages, means, and standard deviations) were performed on all variables and used to summarize the data for the study groups. Differences among the variables between the groups were compared using Chisquare and t-test analysis. Logistic regression was used to run two regression models. The first regression model was adjusted for age, as there was a significant age difference in cervical screening among the women. The second model was a fully adjusted multivariable model that included all variables with a $p$-value of $<0.1$ in the bivariate analysis to explore the association with having had a cervical exam. Statistical Analytical Software 9.4 (SAS Institute, Cary, NC) was used for the analysis and all statistical tests of a two-sided $p$-value of $<0.5$ were considered significant.

\section{Results}

A significant difference was observed between women who previously had a cervical exam and those who did not for participants' age $(p=0.003$; Table 1$)$. Marginal differences were observed for education level, employment status, alcohol consumption, and VIA test results (Table 1). Significant differences were observed for whether participants reported hearing of VIA $(p=0.006)$ and their use of healthcare services $(p=0.014)$ according to previous cervical screening (Table 2). Analysis of the data examining knowledge and perception of participants toward cervical screening showed a significant difference for participants' self-reporting not being aware of which tests to receive $(p<0.001)$, and not knowing when to be screened ( $p<0.001$;Table 3$)$. Table 4 shows the analysis between reproductive history and sexual practices by previous cervical exam. None of the variables was statistically different.

Table 5 shows the Odds Ratio (OR) and 95\% Confidence Interval (CI) of the age-adjusted and fully adjusted logistic regression models for sociodemographic factors, use of health care services, knowledge of cervical screening, reproductive variables of participants, and history of cervical screening. In the fully adjusted model, previous cervical screening among the women varied by age groups. Participants who were $<30$ years of age were 94\% less likely to have received a cervical screening than those $\geq 30$ years of age (OR 0.06; 95\% CI 0.01-0.67). Participants with a tertiary education were six times more likely to have received a cervical screening than those with lower educational levels (OR 5.83; 95\% CI 1.1130.50). Participants who reported that they did not know when to be screened were $73 \%$ less likely to have a cervical exam in the fully adjusted model (OR 0.27 ; 95\% CI $0.01-0.74)$. Tertiary education and not knowing when to be screened were also significantly different in the ageadjusted model (OR 2.25; 95 95\% CI 1.04-4.87 and OR 0.30; 95\% CI 0.17-0.50, respectively).

Additionally, in the age-adjusted model, there was a significant difference by participants' report of their approach towards using health care services. Participants who reported yearly visits to the clinic were twice as likely to have a history of cervical screening compared to those who reported hardly ever visiting the clinic or visiting only when sick (OR 1.97; 95\% CI 1.07-3.63). Participants who reported having heard of VIA were 2.6 times more likely to have been screened previously than those who had not heard of VIA (OR 2.61; 95\% CI 1.45-4.70).

\section{Discussion}

In the fully adjusted model, we observed that age was a significant factor in history of cervical screening. Participants < 30 years of age were $94 \%$ less likely to be screened. This finding is similar to that of a study on CC screening in Kenya which found that women 35-49 years of age were more likely to be screened than women 15-24 years of age [18].

The likelihood of screening among older women may be greater because they have had a longer time to visit health facilities for pregnancy, postnatal care, or other health reasons. This finding has serious implications for the health of younger women living with HIV since they are more likely to develop persistent HPV and preinvasive cervical lesions [10]. This is especially a concern in Swaziland where the prevalence of HIV is very high among women and contributes to high rates of CC. HIV-positive women have a higher chance of developing $\mathrm{CC}$ as much as 10 years before HIV-negative women [19]. This finding highlights the importance of conducting educational and screening interventions for CC among women but especially among younger sexually active women.

We found that women who reported that they did not know when to receive cervical screening were $73 \%$ less likely to be screened. Lack of knowledge about CC, benefits of screening to identify lesions early, and effectiveness of treatment for prevention of invasive disease is a major barrier to cervical screening. A study from Swaziland reported that $46.5 \%$ of women could not correctly name at 
Table 1 Sociodemographic factors and HIV status and having had a cervical screening

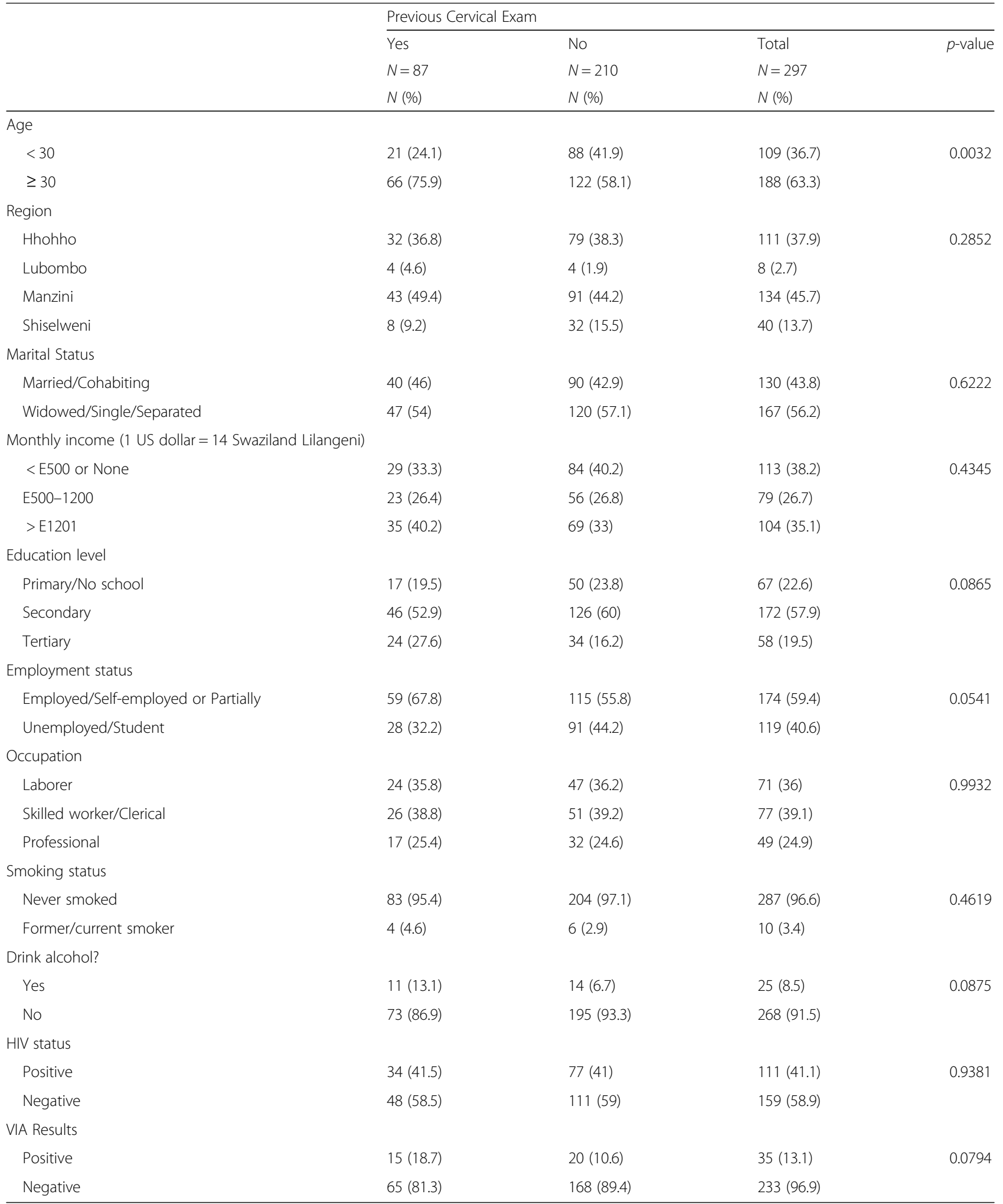

least one symptom of CC [20]. Almost $60 \%$ of participants in this study had misconceptions about the risk factors for $\mathrm{CC}$ and named factors such as witchcraft, abortion, and birth control [20]. Other studies conducted in subSaharan Africa report that lack of knowledge was related to low CC screening among women [18, 21-23]. A study 
Table 2 Cervical cancer knowledge and use of care services by having had a cervical exam

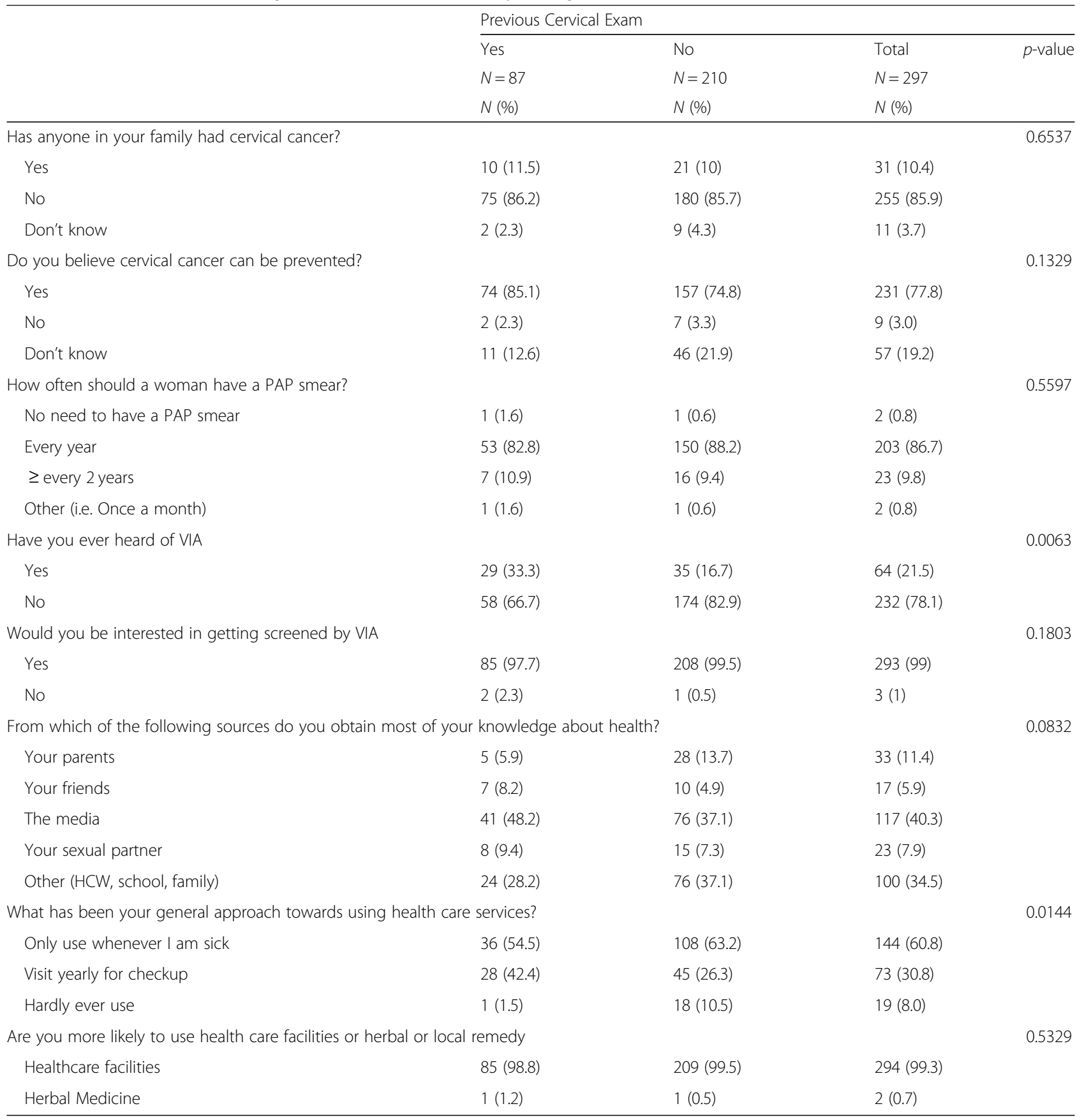

conducted in Kenya found that cervical screening was higher among women who had more media exposure, higher household income, were employed, and visited a health facility in the past 12 months [18]. Another study from Kenya found that knowledge of $\mathrm{CC}$ risk factors was significantly associated with employment status, possibly suggesting that women may become more aware of health matters such as CC screening through their employment [21]. This lack of knowledge contributes to the women's misunderstanding of $\mathrm{CC}$ leading many women to believe that they are not as susceptible and/or at minimal risk for the disease. To address the lack of CC knowledge among patients, healthcare professionals need to communicate information about $\mathrm{CC}$ in a manner that allows patients to ask questions and voice their concerns.

We found that participants with tertiary education were almost six times more likely to receive cervical screening than women with primary or no schooling. This finding is similar to a previous study conducted in Nigeria which found that almost $50 \%$ of women in the 
Table 3 Knowledge and perceptions towards cervical screening among women by previous screening

\begin{tabular}{|c|c|c|c|c|}
\hline & Yes & No & Total & $p$-value \\
\hline & $N=87$ & $N=210$ & $N=297$ & \\
\hline & $N(\%)$ & $N(\%)$ & $N(\%)$ & \\
\hline $\begin{array}{l}\text { Did not know which tests } \\
\text { I should have }\end{array}$ & & & & 0.0007 \\
\hline Yes & $36(41.4)$ & $132(62.9)$ & 168 (56.6) & \\
\hline No & $51(58.6)$ & $78(37.1)$ & $129(43.4)$ & \\
\hline $\begin{array}{l}\text { Doctor has never } \\
\text { recommended screening }\end{array}$ & & & & 0.0938 \\
\hline Yes & $49(56.3)$ & $140(66.7)$ & $189(63.6)$ & \\
\hline No & $38(43.7)$ & $70(33.3)$ & $108(36.4)$ & \\
\hline $\begin{array}{l}\text { Did not know when to } \\
\text { have screening }\end{array}$ & & & & $<0.0001$ \\
\hline Yes & $42(48.3)$ & $158(75.2)$ & $200(67.3)$ & \\
\hline No & $45(51.7)$ & $52(27.8)$ & $97(32.7)$ & \\
\hline $\begin{array}{l}\text { No one known talked } \\
\text { about screening }\end{array}$ & & & & 0.2174 \\
\hline Yes & $45(51.7)$ & $125(59.5)$ & $170(57.2)$ & \\
\hline No & $42(48.3)$ & $85(40.5)$ & $127(42.8)$ & \\
\hline $\begin{array}{l}\text { Worried about tests } \\
\text { finding cancer }\end{array}$ & & & & 0.7395 \\
\hline Yes & $33(37.9)$ & $75(35.9)$ & $108(36.5)$ & \\
\hline No & $54(62.1)$ & $134(64.1)$ & $188(63.5)$ & \\
\hline $\begin{array}{l}\text { Cancer screening tests } \\
\text { cost too much }\end{array}$ & & & & 0.2406 \\
\hline Yes & $14(16.1)$ & $46(22.0)$ & $60(20.3)$ & \\
\hline No & $73(83.9)$ & $163(78.0)$ & $236(79.7)$ & \\
\hline $\begin{array}{l}\text { Cancer screening tests } \\
\text { are painful }\end{array}$ & & & & 0.1420 \\
\hline Yes & $36(41.4)$ & $106(50.7)$ & $142(48.0)$ & \\
\hline No & $51(58.6)$ & $103(49.3)$ & $154(52.0)$ & \\
\hline $\begin{array}{l}\text { Cancer screening tests } \\
\text { are embarrassing and/or } \\
\text { uncomfortable }\end{array}$ & & & & 0.1040 \\
\hline Yes & $26(29.9)$ & $44(20.9)$ & $70(23.6)$ & \\
\hline No & $61(70.1)$ & $166(79.1)$ & $227(76.4)$ & \\
\hline $\begin{array}{l}\text { You don't think you } \\
\text { need testing }\end{array}$ & & & & 0.1823 \\
\hline Yes & $23(26.4)$ & $72(34.3)$ & $95(32.0)$ & \\
\hline No & $64(73.6)$ & $138(65.7)$ & $202(68.0)$ & \\
\hline $\begin{array}{l}\text { You forget to schedule } \\
\text { the tests }\end{array}$ & & & & 0.7652 \\
\hline Yes & $25(28.7)$ & $64(30.5)$ & $89(30.0)$ & \\
\hline No & $62(71.3)$ & $146(69.5)$ & $208(70.0)$ & \\
\hline $\begin{array}{l}\text { Takes too long to get } \\
\text { an appointment }\end{array}$ & & & & 0.8735 \\
\hline Yes & $36(41.4)$ & $89(42.4)$ & $125(42.1)$ & \\
\hline No & $51(58.6)$ & $121(57.6)$ & $172(57.9)$ & \\
\hline $\begin{array}{l}\text { Did not have time for } \\
\text { cancer screening tests }\end{array}$ & & & & 0.5691 \\
\hline Yes & $45(51.7)$ & $101(48.1)$ & $146(49.2)$ & \\
\hline No & $42(48.3)$ & $109(51.9)$ & $151(50.8)$ & \\
\hline
\end{tabular}

Table 4 Reproductive history and sexual practices by having had a cervical exam

\begin{tabular}{|c|c|c|c|c|}
\hline & \multicolumn{4}{|c|}{ Previous Cervical Exam } \\
\hline & Yes & No & Total & $p$-value \\
\hline & $N=87$ & $N=210$ & $N=297$ & \\
\hline & $N(\%)$ & $N(\%)$ & $N(\%)$ & \\
\hline $\begin{array}{l}\text { How many children } \\
\text { do you have? }\end{array}$ & $2.32 \pm 2.24$ & $2.05 \pm 1.66$ & $2.13 \pm 1.84$ & 0.2652 \\
\hline Age at first child & & & & 0.7699 \\
\hline$\leq 17$ & $32(36.8)$ & $74(35.2)$ & $106(35.7)$ & \\
\hline $18-23$ & $46(52.9)$ & $108(51.4)$ & $154(51.8)$ & \\
\hline$\geq 24$ & $9(10.3)$ & $28(13.3)$ & $37(12.5)$ & \\
\hline $\begin{array}{l}\text { How many of your children } \\
\text { did you breastfeed? }\end{array}$ & $2.47 \pm 1.31$ & $2.13 \pm 1.53$ & $2.23 \pm 1.47$ & 0.0913 \\
\hline $\begin{array}{l}\text { Are all your children } \\
\text { from the same partner? }\end{array}$ & & & & 0.3304 \\
\hline Yes & $32(43.2)$ & $84(48)$ & $116(46.6)$ & \\
\hline No & $29(39.2)$ & $52(29.7)$ & $81(32.5)$ & \\
\hline Only 1 child & $13(17.6)$ & $39(22.3)$ & $52(20.9)$ & \\
\hline $\begin{array}{l}\text { Have you ever had } \\
\text { an abortion }\end{array}$ & & & & 0.0574 \\
\hline Yes & $4(4.6)$ & $2(1)$ & $6(2)$ & \\
\hline No & $83(95.4)$ & $206(99)$ & $289(98)$ & \\
\hline Age at first sexual intercourse & & & & 0.9176 \\
\hline$\leq 17$ & $33(37.9)$ & $85(40.5)$ & $118(39.7)$ & \\
\hline $18-23$ & $49(56.3)$ & $113(53.8)$ & $162(54.6)$ & \\
\hline$\geq 24$ & $5(5.7)$ & $12(5.7)$ & $17(5.7)$ & \\
\hline $\begin{array}{l}\text { Number of lifetime } \\
\text { sexual partners }\end{array}$ & & & & 0.5056 \\
\hline 1 & $20(23.0)$ & $56(26.7)$ & $76(25.6)$ & \\
\hline$\geq 2$ & $67(77.0)$ & $154(73.3)$ & $221(74.4)$ & \\
\hline Condom use & & & & 0.7277 \\
\hline Do not use condoms & $18(20.7)$ & $42(20.1)$ & $60(20.3)$ & \\
\hline $\begin{array}{l}\text { Sometimes/Most times/ } \\
\text { Non-Regular partner only }\end{array}$ & $46(52.9)$ & $120(57.4)$ & $166(56.1)$ & \\
\hline $\begin{array}{l}\text { History of any of the } \\
\text { following STIs }\end{array}$ & & & & 0.1245 \\
\hline $\begin{array}{l}\text { Warts, gonorrhea, } \\
\text { syphilis, herpes }\end{array}$ & $28(33.3)$ & $50(24.4)$ & $78(27.0)$ & \\
\hline None & $56(66.7)$ & $155(75.6)$ & $211(73.0)$ & \\
\hline
\end{tabular}

study lacked knowledge of CC screening services and that lack of awareness varied significantly with their level of education [23]. A study from Kenya also found that Pap smear screenings were higher among communities that had higher proportions of women with higher education [18].

\section{Limitations}

This study has limitations that must be considered in interpreting the results. A main limitation is the cross-sectional study design that does not allow for determination of temporal relationships or determination of causality. The small 
Table 5 Regression model for sociodemographic, sexual history, and reproductive practices of having had a cervical screening

\begin{tabular}{|c|c|c|}
\hline & Age-Adjusted OR§ (95\%confidence interval) & Fully Adjusted OR (95\%confidence interval) \\
\hline \multicolumn{3}{|l|}{ Age } \\
\hline$<30$ & & $0.06(0.01-0.67)$ \\
\hline$\geq 30$ & & Referent \\
\hline \multicolumn{3}{|l|}{ Education level } \\
\hline Primary/No school & Referent & Referent \\
\hline Secondary & $1.13(0.59-2.17)$ & $1.48(0.43-5.17)$ \\
\hline Tertiary & $2.25(1.04-4.87)$ & $5.83(1.11-30.50)$ \\
\hline \multicolumn{3}{|l|}{ Employment status } \\
\hline Employed/Self-employed or Partially & $1.39(0.80-2.40)$ & $0.61(0.21-1.74)$ \\
\hline Unemployed/Student & Referent & Referent \\
\hline \multicolumn{3}{|l|}{ Drink alcohol? } \\
\hline Yes & Referent & Referent \\
\hline No & $0.43(0.18-1.01)$ & $0.65(0.12-3.68)$ \\
\hline \multicolumn{3}{|l|}{ VIA Results } \\
\hline Positive & Referent & Referent \\
\hline Negative & $0.51(0.24-1.07)$ & $0.34(0.08-1.38)$ \\
\hline \multicolumn{3}{|c|}{ From which of the following sources do you obtain most of your health knowledge? } \\
\hline Your parents & Referent & Referent \\
\hline Your friends & $2.88(0.72-11.51)$ & $3.87(0.24-62.42)$ \\
\hline The media & $2.27(0.79-6.54)$ & $1.22(0.14-10.74)$ \\
\hline Your sexual partner & $2.46(0.67-9.09)$ & $8.78(0.66-115.91)$ \\
\hline${ }^{\mathrm{a}}$ Other & $1.35(0.45-3.99)$ & $1.56(0.18-13.93)$ \\
\hline \multicolumn{3}{|c|}{ What has been your general approach towards using health care services? } \\
\hline Only use whenever I am sick \& Hardly ever use & Referent & Referent \\
\hline Visit yearly for checkup & $1.97(1.07-3.63)$ & $1.87(0.74-4.72)$ \\
\hline \multicolumn{3}{|c|}{ Has any of the following ever prevented you from being tested for cervical cancer? } \\
\hline \multicolumn{3}{|l|}{ Not knowing which tests I should have } \\
\hline Yes & $0.39(0.23-0.65)$ & $0.54(0.22-1.37)$ \\
\hline No & Referent & Referent \\
\hline \multicolumn{3}{|l|}{ Doctor has never recommended screening } \\
\hline Yes & $0.61(0.36-1.03)$ & $1.36(0.50-3.65)$ \\
\hline No & Referent & Referent \\
\hline \multicolumn{3}{|l|}{ Didn't know when to have screening } \\
\hline Yes & $0.30(0.17-0.50)$ & $0.27(0.01-0.74)$ \\
\hline No & Referent & Referent \\
\hline \multicolumn{3}{|l|}{ Have you ever heard of VIA } \\
\hline Yes & $2.61(1.45-4.70)$ & $1.78(0.47-6.75)$ \\
\hline No & Referent & Referent \\
\hline How many of your children did you breastfeed? & $1.13(0.94-1.36)$ & \\
\hline \multicolumn{3}{|l|}{ Have you ever had an abortion } \\
\hline Yes & $5.06(0.88-29.12)$ & $2.60(0.24-28.82)$ \\
\hline No & Referent & Referent \\
\hline
\end{tabular}

${ }^{\mathrm{a} O t h e r}=$ Health-care worker, school, family 
sample size is another limitation that might have prevented significant findings for variables other than those found significant in the study. Since the study sample was drawn from patients attending healthcare facilities, the results are not generalizable to women who did not visit healthcare facilities. Further, the sample may not be fully representative of women attending clinics in Swaziland. However, we recruited women from the main hospitals in three of the four regions of Swaziland. Finally, the data were self-reported and may be subject to social desirability bias.

Regardless of the limitations, this study identified factors such as age, education, and knowledge of when to obtain cervical screening as important factors influencing whether a woman had previous cervical screening. Identifying these barriers to cervical screening is important in Swaziland because of the very high HIV prevalence among women and high rate of CC. VIA is the cervical screening method most commonly used in Swaziland, however, $78 \%$ of women in this study reported that had not previously heard of VIA. The proportion of women who reported that they had heard of VIA and were screened was twice that of women who said they had not previously heard of VIA. Thus, it is crucial for programs to focus on providing CC education and ensuring that women with less education are knowledgeable about CC. Future prevention and intervention strategies should focus on sociodemographic factors, health-seeking behaviors, and knowledge of CC in order to encourage women in Swaziland to seek cervical screening.

\section{Abbreviations \\ ART: Antiretroviral therapy; CC: Cervical Cancer; Cl: Confidence interval; HPV: Human Papillomavirus; hr-HPV: High risk Human Papillomavirus; HTC: HIV treatment and care; OR: Odds ratio; STI: Sexually transmitted infections; VIA: Visual inspection with acetic acid}

\section{Acknowledgements}

We thank the women who participated in this research as well as the nurses and hospital staff who helped to facilitate this study.

\section{Authors' contributions}

The study was conceived and designed by PEJ, POP, and SMH. LAP, SR and IOA analyzed the data and all authors interpreted the data. IOA drafted the manuscript and all authors reviewed, revised, and approved the manuscript.

\section{Funding}

This research was funded by the Cancer Research Experiences for Students (CaRES) grant no. 5R25 CA076023 from the National Cancer Institute, National Institutes of Health $(\mathrm{NIH})$ and the Minority Health International Research Training (MHIRT) grant no. T37-MD001448 from the National Institute on Minority Health and Health Disparities, NIH, Bethesda, MD, USA.

\section{Availability of data and materials}

The datasets used and analyzed during the current study are available from the corresponding author upon reasonable request.

\section{Ethics approval and consent to participate}

Prior to its implementation, this study was approved by the Institutional Review Board at the University of Alabama at Birmingham, and the Scientific and Ethics Committee, Ministry of Health and Social Welfare, Swaziland.
Consent for publication

Not applicable.

\section{Competing interests}

The authors declare that they have no competing interests.

\section{Author details}

'Department of Epidemiology, School of Public Health, University of Alabama at Birmingham, 1655 University Boulevard, Birmingham, AL 35294-0022, USA. ${ }^{2}$ Ministry of Health and Social Welfare, 2nd Floor Ministry of Justice \& Constitutional Affairs Building, Mhalambanyatsi Road, Mbabane, Swaziland. ${ }^{3}$ Care and Treatment Lead for the President's Emergency Plan for AIDS Relief (PEPFAR), Jubela Street; Kent Rock, Mbabane, Swaziland.

Received: 20 November 2019 Accepted: 20 February 2020

Published online: 05 March 2020

\section{References}

1. American Cancer Society. The Global Impact of Cervical Cancer. 2017 [cited 2019 Nov 19]. Available from: https://www.fightcancer.org/policy-resources/ global-impact-cervical-cancer.

2. Gakidou E, Nordhagen S, Obermeyer Z. Coverage of cervical cancer screening in 57 countries: low average levels and large inequalities. PLoS Med. 2008;5(6):e132.

3. Branca M, Garbuglia AR, Benedetto A, Cappiello T, Leoncini L, Migliore G, et al. Factors predicting the persistence of genital human papillomavirus infections and PAP smear abnormality in HIV-positive and HIV-negative women during prospective follow-up. Int J STD AIDS. 2003 Jun;14(6):417-25.

4. De Vuyst H, Lillo F, Broutet N, Smith JS. HIV, human papillomavirus, and cervical neoplasia and cancer in the era of highly active antiretroviral therapy. Eur J Cancer Prev. 2008 Nov;17(6):545-54.

5. Parham GP, Sahasrabuddhe W, Mwanahamuntu MH, Shepherd BE, Hicks ML, Stringer EM, et al. Prevalence and predictors of squamous intraepithelial lesions of the cervix in HIV-infected women in Lusaka, Zambia. Gynecol Oncol. 2006;103(3):1017-22.

6. World Health Organization. Human papillomavirus (HPV) and cervical cancer. 2019. [Cited 2019 Nov 19]. Available from: http:/www.who.int/ mediacentre/factsheets/fs380/en/.

7. Bruni L, Albero G, Serrano B, Mena M, Gómez D, Muñoz J, Bosch FX, de Sanjosé S. Human Papillomavirus and Related Diseases in Swaziland. ICO/ IARC Information Centre on HPV and Cancer (HPV Information Centre); 2019 [cited 2019 Nov 19]. 70p. Available from: https://hpvcentre.net/statistics/ reports/SWZ.pdf.

8. Ginindza TG, Dlamini X, Almonte M, Herrero R, Jolly PE, Tsoka-Gwegweni $J M$, et al. Prevalence of and associated risk factors for high risk human papillomavirus among sexually active women, Swaziland. PLoS One. 2017; 12(1):e0170189.

9. Jolly PE, Mthethwa-Hleta S, Padilla LA, Pettis J, Winston S, Akinyemiju TF, et al. Screening, prevalence, and risk factors for cervical lesions among HIV positive and HIV negative women in Swaziland. BMC Public Health. 2017 Feb 21:17(1):218.

10. Avert. HIV and AIDS in Eswatini. 2019; cited 2019 Nov 19]. Available from: https://www.avert.org/professionals/hiv-around-world/sub-saharan-africa/ swaziland.

11. UNICEF. Swaziland: HIV and AIDS. [cited 2019 Nov 19]. Available from: http://www.unicef.org/swaziland/hiv_aids.html.

12. Moscicki AB, Hills N, Shiboski S, Powell K, Jay N, Hanson E, et al. Risks for incident human papillomavirus infection and low-grade squamous intraepithelial lesion development in young females. JAMA. 2001 Jun 20; 285(23):2995-3002.

13. Ribeiro AA, Costa MC, Alves RR, Villa LL, Saddi VA, Carneiro MA, et al. HPV infection and cervical neoplasia: associated risk factors. Infect Agent Cancer. 2015;10:16.

14. Ononogbu U, Almujtaba M, Modibbo F, Lawal I, Offiong R, Olaniyan O, et al. Cervical cancer risk factors among HIV-infected Nigerian women. BMC Public Health. 2013;13:582.

15. Coronado Interis E, Anakwenze CP, Aung M, Jolly PE. Increasing Cervical Cancer Awareness and Screening in Jamaica: Effectiveness of a TheoryBased Educational Intervention. Int J Environ Res Public Health. 2015;13(1): ijerph13010053. 
16. Alliance for Cervical Cancer Prevention. Cervical Cancer Prevention Fact Sheet: New evidence on the impact of cervical cancer screening and treatment using HPV DNA tests, visual inspection, or cytology. 2009 [cited 2019 Nov 19]. Available from: http://www.rho.org/files/ACCP_screening factsheet_July09.pdf.

17. Sherris J, Wittet S, Kleine A, Sellors J, Luciani S, Sankaranarayanan R, et al. Evidence-based, alternative cervical cancer screening approaches in lowresource settings. Int Perspect Sex Reprod Health. 2009 Sep;35(3):147-54

18. Tiruneh FN, Chuang KY, Ntenda PAM, Chuang YC. Individual-level and community-level determinants of cervical cancer screening among Kenyan women: a multilevel analysis of a Nationwide survey. BMC Womens Health. 2017 Nov 15;17(1):109.

19. Kahesa C, Mwaiselage J, Wabinga HR, Ngoma T, Kalyango JN, Karamagi CA. Association between invasive cancer of the cervix and HIV-1 infection in Tanzania: the need for dual screening. BMC Public Health. 2008;8:262.

20. Ngwenya D, Huang SL. Knowledge, attitude and practice on cervical cancer and screening: a survey of men and women in Swaziland. J Public Health (Oxf). 2018;40(3):e343-50

21. Gatumo M, Gacheri S, Sayed AR, Scheibe A. Women's knowledge and attitudes related to cervical cancer and cervical cancer screening in Isiolo and Tharaka Nithi counties, Kenya: a cross-sectional study. BMC Cancer. 2018 Jul 18;18(1):745.

22. Matenge TG, Mash B. Barriers to accessing cervical cancer screening among HIV positive women in Kgatleng district, Botswana: a qualitative study. PLoS One. 2018;13(10):e0205425.

23. Nwankwo KC, Aniebue UU, Aguwa EN, Anarado AN, Agunwah E. Knowledge attitudes and practices of cervical cancer screening among urban and rural Nigerian women: a call for education and mass screening. Eur J Cancer Care (Engl). 2011 May;20(3):362-7.

\section{Publisher's Note}

Springer Nature remains neutral with regard to jurisdictional claims in published maps and institutional affiliations.

Ready to submit your research? Choose BMC and benefit from:

- fast, convenient online submission

- thorough peer review by experienced researchers in your field

- rapid publication on acceptance

- support for research data, including large and complex data types

- gold Open Access which fosters wider collaboration and increased citations

- maximum visibility for your research: over $100 \mathrm{M}$ website views per year

At $\mathrm{BMC}$, research is always in progress.

Learn more biomedcentral.com/submissions 